\title{
A tiered system for assessing the risk of genetically modified plants to non-target organisms
}

Monica GARCIA-ALONSO ${ }^{1}$, Erik JACOBS ${ }^{2}$, Alan RAYBOULD ${ }^{1}$, Thomas E. NICKSON ${ }^{3}$, Peter SOWIG ${ }^{4}$, Hilde WILLEKENS $^{5}$, Pier VAN DER KOUWE ${ }^{6}$, Raymond LAYTON ${ }^{7}$, Firoz AMIJEE ${ }^{8}$, Angel M. FUENTES ${ }^{8}$ and Francesca TENCALLA $^{2^{*}}$

${ }^{1}$ Syngenta, Jealott's Hill International Research Centre, Bracknell, RG42 6EY, United Kingdom

${ }^{2}$ Monsanto Europe, Avenue de Tervueren 270 - 272, B-1150 Brussels, Belgium

${ }^{3}$ Monsanto Company, 800 N. Lindbergh Blvd, St. Louis, MO 63141, USA

${ }^{4}$ Bayer CropScience, Industriepark Höchst H871, D-65926 Frankfurt am Main, Germany

${ }^{5}$ Syngenta International AG, Avenue Louise 240, Box 4, B-1050 Brussels, Belgium

${ }^{6}$ Bayer CropScience, Rue Jean-Marie Leclair 16, CP 106, F-69266 Lyon Cedex 09, France

${ }^{7}$ Pioneer Hi-Bred International, 7300 NW 62nd Avenue, PO Box 1004, Johnston IA 50131-1004, USA

${ }^{8}$ Pioneer Overseas Corporation, Avenue des Arts 44, B-1040 Brussels, Belgium

Representatives of the developers of modern agricultural biotechnology are proposing a tiered approach for conducting non-target organism risk assessment for genetically modified (GM) plants in Europe. The approach was developed by the Technical Advisory Group of the EuropaBio Plant Biotechnology Unit (http:// www.europabio.org/TAG.htm) and complements other international activities to harmonize risk assessment. In the European Union (EU), the principles and methods to be followed in an environmental risk assessment for the placing on the market of GM plants are laid out in Annex II of Directive 2001/18/EC on the deliberate release into the environment of GMOs, Commission Decision 2002/623/EC and Regulation (EC) No. 1829/2003. Additional information is provided in the European Food Safety Authority guidance document of 2004. However, risk assessment for effects to non-target organisms could benefit from further clarification and remains the subject of much discussion in Europe. The industry-wide approach developed by EuropaBio is based on the fundamental steps of risk evaluation, namely hazard and exposure assessment. It follows a structured scheme including assessment planning, product characterization and assessment of hazard/exposure (Tier 0), single high dose and dose response testing (Tier 1), refined hazard characterization and exposure assessment (Tier 2) and further refined risk assessment experiments (Tier 3). An additional tier (Tier 4) was included to reflect the fact that post-market activities such as monitoring are required under Directive 2001/18/EC. The approach is compatible with conditions of commercial release in the EU and around the world.

Keywords: risk assessment / tiered approach / European legislation / genetically modified organisms / EuropaBio

\section{INTRODUCTION}

Scientific risk assessment is the foundation upon which regulatory decisions are made for genetically modified organisms (GMOs) such as GM plants. Environmental risk assessment is one component of a complete risk assessment; the other is food and feed safety assessment. A well-constructed environmental risk assessment organizes existing knowledge on the nature of the introduced trait, the characteristics of the GM plant compared to its non-GM counterpart, the nature of the likely receiving environment, the extent of the release, and the interactions among these elements. Information is systematically acquired for the purpose of assessing the potential for a GM trait or plant to be hazardous, the likelihood for the hazard to be realized, and the consequences should this occur. Competent authorities evaluate the environmental risk assessment information

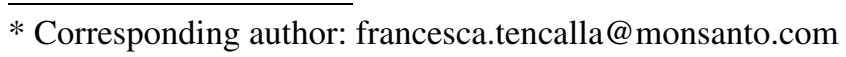




\section{Garcia-Alonso et al.}

based on existing regulations and relevant guidelines in order to decide whether to authorize commercialization of a particular GM plant for import or deliberate release into the environment (i.e. cultivation).

Current European legislation (Annex II of Directive 2001/18/EC on the deliberate release into the environment of genetically modified organisms, Commission Decision 2002/623/EC establishing guidance notes supplementing Directive 2001/18/EC, Regulation (EC) No. 1829/2003 on genetically modified food and feed and European Food Safety Authority guidance document of 2004) provides general guidance on conducting an environmental risk assessment for GM plants. The guidance is not prescriptive, since environmental risk assessment is conducted case-by-case. Consequently, the data required can vary considerably, depending on the GM plant under evaluation, the intended use (import or cultivation), and different interpretations of the legislation.

For several reasons, the GM plant environmental risk assessment for non-target organisms would benefit from further clarification. First, the known characteristics of the introduced trait and the recipient plant provide important background or baseline information on the potential for adverse effects on non-target organisms; the methods employed for organizing this existing knowledge and subsequently acquiring hazard and exposure information should be more clearly explained. Furthermore, when laboratory testing is undertaken, justification for the experimental tests used, the doses chosen and the organisms selected is needed. There should be clarification of which studies and information are appropriate for an imported product that is used for food and feed, compared to a product that is intended for cultivation in the European Union (EU). Developing a scientific consensus approach for assessing potential environmental risk to non-target organisms, compatible with regulatory requirements, is therefore an important goal.

This paper describes a consensus approach proposed by companies member of the Technical Advisory Group (TAG) of the EuropaBio Plant Biotechnology Unit (http://www.europabio.org/TAG.htm) based on many years of combined experience in the field of GM plant risk assessment. EuropaBio is an organization comprised of "bioindustries"; further information can be found under http://www.europabio.org. The proposed tiered risk assessment scheme is intended to provide risk assessors with a common approach to conducting the environmental risk assessments necessary to fulfil the requirements set out by current European legislation. The approach guides risk assessors through the data collection and data production in a logical and practical manner in order to perform effective environmental risk assessments. For this, all the major requirements and recommendations to conduct an environmental risk assessment are taken into account, including hazard and exposure evaluation, the need to consider immediate and delayed effects due to direct and indirect interactions with the GM plan and the need for a monitoring plan.

\section{EU LEGISLATION ON ENVIRONMENTAL RISK ASSESSMENT FOR GM PLANTS}

In the EU, every notification concerning the deliberate release of a GM plant in the environment must include a complete set of data to be submitted before the application is considered acceptable and a scientific evaluation can begin. This includes a detailed environmental risk assessment in accordance with the principles in Annex II of Directive 2001/18/EC, the complementary guidance notes laid down in Commission Decision 2002/623/EC and the EFSA guidance document (EFSA, 2004).

The basis of the environmental risk assessment is a comparison between the GM plant and an appropriate non-GM counterpart. In most cases, the comparator is the corresponding traditionally cultivated non-GM plant, including the agricultural practices used to grow it. This comparator serves as a baseline for the environmental risk assessment, which starts by evaluating "familiarity" 1 and "substantial equivalence", as described by OECD (OECD, 1993a and b) and WHO/FAO (WHO/FAO, 2000). Once the similarities and differences between the GM plant and its comparator are established, the risk assessment can focus on the environmental or food/feed safety and nutritional impact of any intended or unintended differences (EFSA, 2004). If for example the only difference found between the GM plant and the nonGM comparator is the newly expressed protein(s), the risk

\footnotetext{
1 The concept of familiarity is based on the fact that most GM plants are developed from organisms such as crop plants with a well known biology. It is therefore appropriate to draw on this previous knowledge and experience for a risk assessment, and to use the non-GM plant as a comparator in order to highlight differences with the genetic modification and subsequent management of the GM plant (EFSA, 2004).

2 The concept of substantial equivalence is based on the idea that an existing organism used as food/feed with a history of safe use can serve as a comparator when assessing the safety of a GM plant. The GM plant and the non-GM counterpart are compared with regard to molecular, agronomic and morphological characteristics, as well as chemical composition (EFSA, 2004).
} 
assessment can focus on the potential effects of this $\operatorname{protein}(\mathrm{s})$.

In the complementary guidance notes laid down in Commission Decision 2002/623/EC it is suggested that, when drawing conclusions regarding potential environmental risks, the evaluation should be presented in six distinct steps: identification of the characteristics of the GM plant which may cause potential adverse effects (Step 1), evaluation of the likelihood of occurrence of each adverse effect (Steps 2 and 3), estimation of the risks posed by the GM plant (Step 4), application of risk management strategies (Step 5) and determination of the overall risk of the GM plant (Step 6). These correspond to the normal steps for any sound risk evaluation: assessment of hazard, assessment of exposure and combining these assessments to characterize risk. They allow the organization of available information and any resulting recommendations for risk management and/or monitoring in a comprehensive manner that permits regulators to conclude on questions 4 and 5 of Annex II part D.2, which refer to potential risks to non-target organisms.

Directive 2001/18/EC also establishes that the environmental risk assessment must assess any immediate or delayed adverse effects due to direct and indirect interactions of the GM plant with non-target organisms ${ }^{3}$. Finally, a proposal for a post-market monitoring plan is requested, which should be constructed in accordance with Annex VII to the Directive and corresponding guidance notes, laid down in Council Decision 2002/811/ EC.

\section{PRINCIPLES OF RISK ASSESSMENT}

Risk is a function of hazard and the likelihood that this hazard will be realized. According to the European

\footnotetext{
3 According to Directive 2001/18/EC, "direct effects" refers to primary effects on human health or the environment which are a result of the GMO itself and which do not occur through a causal chain of events; "indirect effects" refers to effects on human health or the environment occurring through a causal chain of events, through mechanisms such as interactions with other organisms, transfer of genetic material, or changes in use or management. Observations of indirect effects are likely to be delayed; "immediate effects" refers to effects on human health or the environment which are observed during the period of the release of the GMO. Immediate effects may be direct or indirect; "delayed effects" refers to effects on human health or the environment which may not be observed during the period of the release of the GMO but become apparent as a direct or indirect effect either at a later stage or after termination of the release.
}

Commission (EC, 2000), risk assessment is "a process of evaluation including the identification of the attendant uncertainties of the likelihood and severity of an adverse effect(s)/event(s) occurring to man or the environment following exposure under defined conditions to a risk source(s)".

As in any risk assessment, an environmental risk assessment for non-target organisms identifies potential hazards, estimates the likelihood of the hazards being realized (exposure), analyses the potential severity of the consequences of the hazards being realized and ultimately characterizes risk. An environmental risk assessment is guided by scientific principles and takes into account all available information, including expert advice and a caseby-case approach for information requirements (BSP, 2000; OECD, 1993a). Also, risks should be compared to those posed by appropriate conventional non-GM counterparts, and risk assessments should be recursive, with conclusions being re-examined when new information comes to light. An important addition to these principles, highlighted by the Cartagena Protocol on Biosafety (BSP, 2000), was the recognition that the lack of information is not indicative of "a particular level of risk, an absence of risk or an acceptable risk".

\section{Hazard assessment}

Hazard is "the potential of an identified source to cause an adverse effect" (EFSA, 2004). In the case of GM plants, environmental hazard assessment includes the examination of the potential for the GM plant and introduced trait to cause adverse effects on non-target organisms. The evaluation must link "assessment endpoints", such as those characteristics or attributes of non-target organisms that make them beneficial to the environment, with scientific data (Calow, 1998; Newman, 1998; US EPA, 1998). For non-target organisms, hazard assessment focuses on the toxic effects of the protein(s) expressed by the GM plant, to assess potential direct and indirect harmful effects on populations of organisms valued for their ecological functions (e.g. pollinators, parasitoids, predators, decomposers, etc.). Knowledge of the nature of the inserted trait and the ecology of the conventional plant are critical to this assessment (EFSA, 2004; OECD, 1993a).

\section{Exposure assessment}

Exposure is the extent of contact between the GM plant or the protein(s) it produces with the non-target organisms in the environment (definition based on US EPA, 1998). Exposure is a function of concentration, time (persistence) 


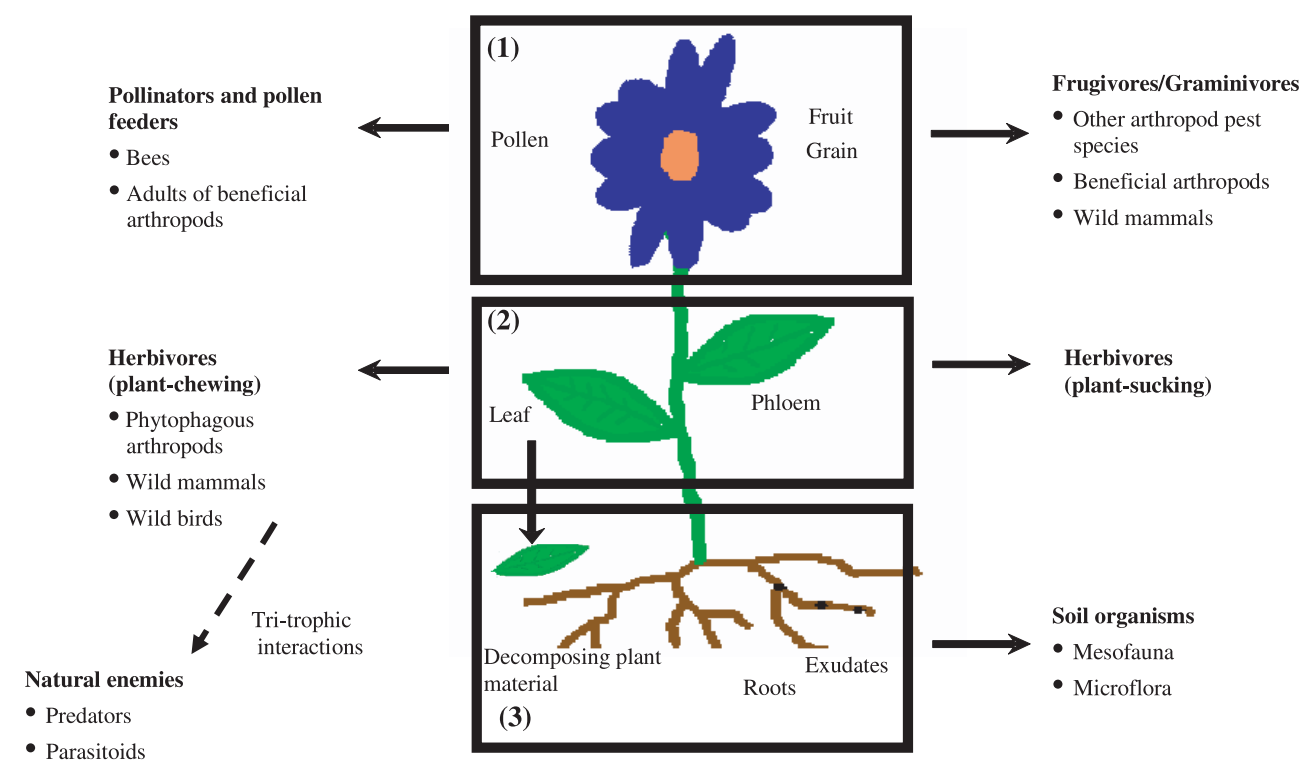

Figure 1. Exposure assessment: main routes of exposure of non-target organisms to the GM plant and the newly expressed protein(s). The plant can be divided in the three main compartments that serve as food to non-target organisms: (1) Flower compartment, comprising either pollen, fruit or grain; (2) Plant tissue compartment: green tissue (i.e. leaf and stalk) or phloem; (3) Soil compartment: roots, root exudates and decomposing plant material. Black arrows indicate the main groups of non-target organisms that can be directly exposed to each of those plant parts. The dotted arrow indicates indirect exposure through tritrophic interactions to natural enemies feeding on non-target arthropods that fed previously on the GM plant.

and frequency. The risk assessment must estimate how much of the potential hazard agent could be released, how often it will be released, and how long it will remain in the environment above a level considered harmful. Exposure pathways and scenarios are related to the basic biology and the agricultural management of the GM plant.

Environmental fate of plant materials and proteins, including exposure resulting from gene flow, are important considerations in exposure assessment for GM plants. Knowledge of the ecology of a GM plant as it relates to interactions with animals and micro-organisms and expression patterns of the introduced protein are also important. These interactions can be divided into groups according to trophic level and taxonomy (Fig. 1). Direct dietary exposure to the introduced protein will only occur if it is expressed in the plant part on which the organism feeds (e.g. leaves, roots, grains or pollen). Secondary exposure may occur if the non-target organism of interest is a predator or parasitoid of a pest that has ingested the protein. Exposure characterization is a logical method to assess which non-target organisms will come in contact with the introduced trait and to develop exposure scenarios and pathways for inclusion in the risk assessment.

\section{PROPOSAL FOR NON-TARGET ORGANISM RISK ASSESSMENT USING A TIERED APPROACH}

Numerous authors and regulatory authorities have proposed tiered approaches for the environmental risk assessment of chemical substances and GM plants (Andow and Zwahlen, 2006; Dutton et al., 2003; Nickson and McKee, 2002; Rose, 2006; Schuler et al., 2000; US EPA, 1998 and 1999; Van Leuven, 1996; Wilkinson et al., 2003). This approach provides a systematic progression where information is collected and subsequently integrated into the risk assessment (US EPA, 2001). The information collected in lower tiers directs the extent and nature of the experimentation conducted in higher tiers. Progressing in a structured way allows field testing, when required, to be better targeted and therefore of higher predictive value. The tiered approach is consistent with the iterative or recursive nature of risk assessment where conclusions are reviewed when new knowledge is obtained (US EPA, 1998).

In general, lower tiers involve conservative assumptions and worst-case conditions in the studies conducted. If the risks evaluated at any stage are shown 
to be negligible or acceptable with reasonable certainty, or it is considered that sufficient information to make a regulatory decision has been collected, then the assessment can stop ${ }^{4}$. However, if unacceptable risks are identified or unacceptable uncertainty remains, the assessment is refined at higher tiers. Post-market monitoring is also a tool available to address uncertainty and allow collection of additional information following the commercialization of a GM plant.

Based on the requirements of EU legislation and on various approaches published in the scientific literature, the Technical Advisory Group of EuropaBio's Plant Biotechnology Unit proposes a tiered approach that includes assessment planning, product characterization and assessment of hazard/exposure (Tier 0), single high dose and dose response testing (Tier 1), refined hazard characterization and exposure assessment (Tier 2), and further refined risk assessment experiments (Tier 3). An additional tier (Tier 4) is included to reflect the fact that post-market activities such as monitoring are required under Directive 2001/18/EC. The various tiers are described in the following section and summarized in Figures 2 and 3.

\section{Tier 0 - Assessment planning, product characterization and identification of hazard/exposure}

The first tier proposed, Tier 0, is where the risk assessment is planned. All available information on the product (GM plant and introduced trait), the receiving environment, the extent of the release and likely interactions between these factors is gathered, potential hazard and exposure are analyzed and necessary further tiers in the assessment (if any) are then planned based on this data. In some environmental risk assessment frameworks (US EPA, 1998), Tier 0 is referred to as a "problem formulation step" that focuses the assessment and ensures that conclusions will be relevant to decision-making.

As described above, EU legislation requires that a complete set of studies be performed to generate the necessary data that allows regulators to conduct a scientific assessment on submitted GM plant applications.

\footnotetext{
4 Experimental work stops when the risk can be characterized as acceptable with reasonable certainty. However, as noted earlier, risk assessment is a recursive process where new information is evaluated and risk conclusions can be reconsidered. Final decisions on the acceptability of risk are made by authorities responsible for decision-making.
}

Therefore, at the start of any risk assessment process, a large amount of information on the GM plant under evaluation is already available. This includes for example a detailed characterization of the GM plant, which will have undergone extensive molecular and expression analysis as well as compositional and agronomic analysis. Molecular and expression analysis provides data on the inserted gene and the newly expressed protein(s), including activity, mode and/or site of action, expression in the plant and toxicity to non-target organisms. According to the principles of "familiarity" and "substantial equivalence", compositional and agronomic analysis shows whether there are differences between the GM and non-GM comparator plant in compositional factors such as nutrients and anti-nutrients or agronomic/ phenotypic characteristics that might affect non-target organisms. At Tier 0, other information sources may also be taken into account, including experience from countries outside of the EU and public literature.

Based on this initial data package, a preliminary assessment of hazard and exposure is conducted following a weight of evidence approach. In some cases (e.g. a nonpesticidal GM crop for which a large amount of information is available due to large-scale planting in countries outside of the EU), risk to non-target organisms may be characterized sufficiently for decision-making based on the weight of evidence collected at Tier 0 . If this is not the case, the risk assessor will plan further studies and progress to the next tiers of the evaluation.

\section{Tier 1 - Single high dose and dose-response testing}

In Tier 1, data are generated in the laboratory for a limited number of carefully selected species that are representative of the different taxonomic and functional groups of non-target organisms expected to be exposed (see text box) and for which insufficient information is available, based on the hazard/exposure assessment conducted in Tier 0 .

Tier I tests are designed to be conservative, because at this stage of the risk assessment, the aim is to maximize the possibility of detecting any hazard, i.e. avoid false negatives (Type II errors) (Marvier, 2002). Several factors make these tests conservative compared to exposure under field conditions. First of all, test organisms are exposed to a level of the newly expressed GM plant protein(s) (as pure protein or plant material; see text box) higher than what would be encountered in the environment. In some test systems, a single dose corresponding to the maximum dose deliverable ("the maximum hazard dose") is used, 


\section{Garcia-Alonso et al.}

whereas in others it is a multiple of the expected environmental concentration (in tests with pure proteins, a dose of 10 times the expected environmental exposure is generally targeted); the choice of dose level depends on the hypothesis being tested and the practicalities of the test system. Furthermore, non-target organisms are exposed for a duration that could represent an important part of their lifetime and no other food sources are made available. Finally, species that are most likely to be sensitive to the protein can be used to increase the likelihood of detecting a hazard. For example, if the target pest is a beetle, ladybirds are likely to be more sensitive to the protein than are lacewings. Selecting species that are likely to be sensitive reduces the need to extrapolate the effects on representative species to potentially more sensitive species (see below).

In Tier 1, laboratory tests are preferred over field studies, as they have the advantage that complicating ecological factors such as humidity, soil composition or other are removed, so that a direct link between the effects observed and the GM plant or protein(s) can be made.

If no adverse effects on the representative species are detected, it can be inferred that, under more realistic exposure conditions, the hazard to non-target organisms that are potentially exposed but have not been tested will also be negligible; no further testing is then necessary.

When effects are seen for certain species in the conservative single high dose tests, dose-response studies can be conducted to better characterize hazard. If unacceptable risks still cannot be ruled out, higher tier tests should be done to refine the risk assessment. These are designed to reflect more realistic conditions and are based on the hypothesis that factors in the field will likely mitigate the effects observed in the laboratory. Several methods are available for higher tier testing and no single method is the obvious next tier for all situations; the risk assessor should choose the method that is the most effective to test the risk hypothesis. Importantly, it is the concept of interjecting increasing realism that characterizes higher tier testing and provides the risk assessor with maximum flexibility to adapt to the results obtained within any tier. Labeling particular methods and assigning them to a particular tier can be rigid and might unnecessarily restrict the design of an appropriate higher tier experiment. As such, higher tiers are cautiously defined in the next sections to reinforce their primary purpose, which is to refine the risk assessment.

\section{RECOMMENDATIONS FOR SELECTION OF REPRESENTATIVE SPECIES AND TEST MATERIALS}

\section{Test species}

The non-target organisms potentially at risk will depend on the GM plant, the nature of the introduced trait and the environment where the plant is released. Appropriate test species should therefore be chosen case-by-case. GM plants tested to date have used organisms selected from groups which include mammals and a bird (data are already generated for use in the human safety package), a fish, a freshwater invertebrate, terrestrial arthropods (predators, parasitoids, pollinators) and soil organisms (for the terrestrial environment, soil function has proven to be a good measure in many cases because it integrates all the various influencing factors). These groups are appropriate because they are functionally important (Fig. 1). Furthermore, laboratory testing methods, originally developed and validated for chemical pesticides, are available for representatives of each functional group (Barrett et al., 1994; Candolfi et al., 2000). Ideally, the selected species are present in the environment where the GM plant will be released and are widely recognized as representative of potentially exposed taxonomic and functional groups.

\section{Test materials}

Various test materials can be used in the laboratory studies, including plant material and protein purified either from the GM plant or from a microbial expression system. The choice of the most appropriate test substance is made case-by-case based on the overall testing strategy and the requirements of each particular test. Plant purified protein is useful for dose-response testing or for studies where concentrations significantly above those expected in the field are desired. However, this material is not always available or practical, as extraction methods can be complex and expression levels are often so low that unrealistically large amounts of plant material are needed to obtain enough purified protein for testing. Microbially-produced protein is useful when high safety factors are wanted. Importantly, studies must be done to establish the equivalence of the microbially-expressed protein to that expressed in the GM plant. Lastly, GM plant material is another option for consideration as a test material. It has the advantage of being a "realistic" test substance for organisms that feed on the plant. However, the assessment will be limited to the expression levels. 
Tier 0

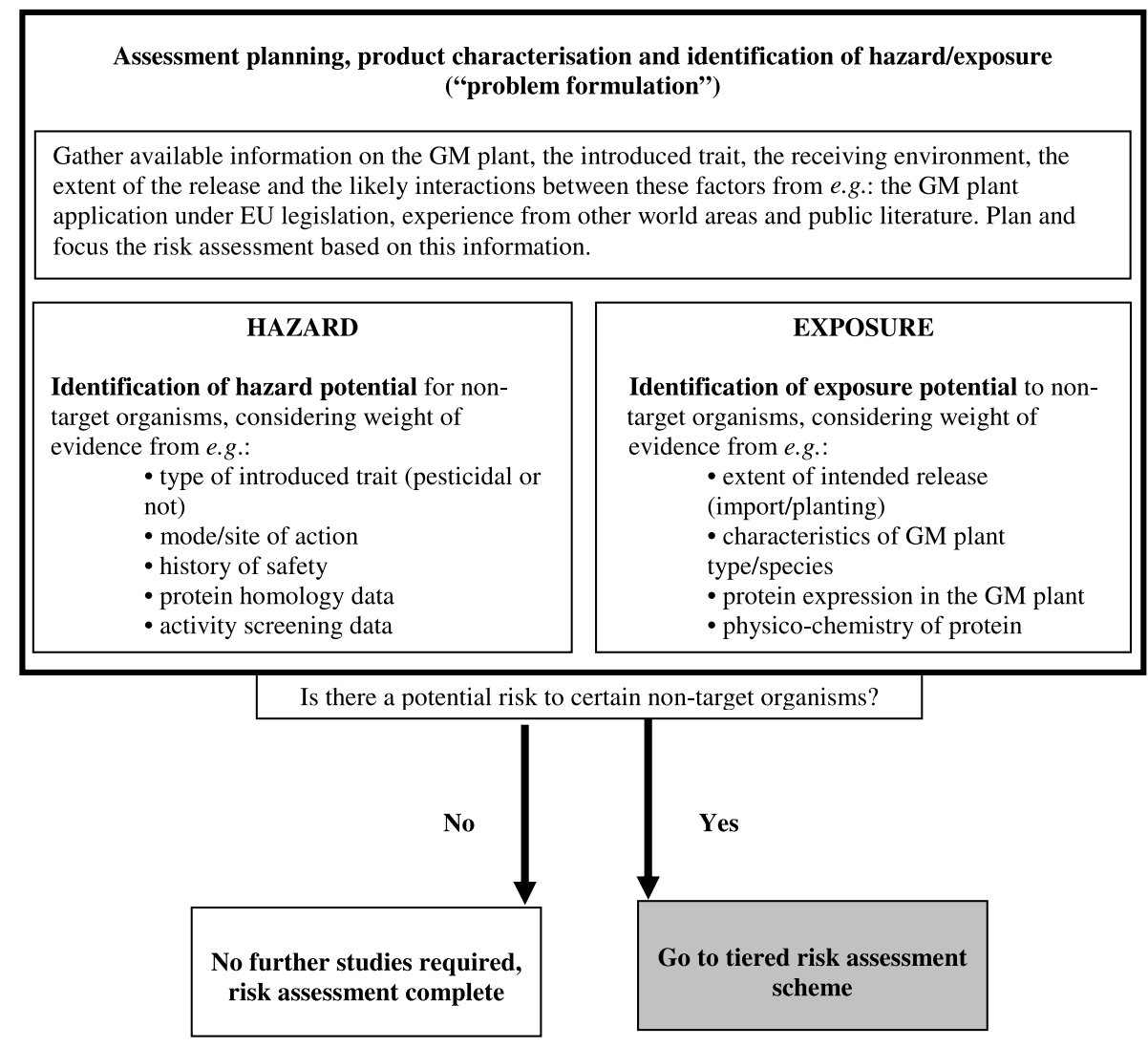

Figure 2. Decision tree for tiered environmental risk assessment of GM plants to non-target organisms (Tier 0).

\section{Tier 2 - Refined hazard characterization and exposure assessment}

In Tier 2, additional hazard characterization studies can be conducted in the laboratory. Alternatively, more realistic exposure scenarios may be considered by refining the examination of plant life cycle, ecology and behavior of the non-target organism or relevant climatic and geographical factors.

If the risks are shown to be negligible or acceptable with reasonable certainty, or it is considered that enough information is available to make a regulatory decision, the risk assessment can stop at this tier. If the Tier 2 evaluation however still indicates a potential risk to certain non-target organisms or further information is required for decisionmaking, then higher-tier tests with these species may be carried out (Tier 3), or potential mitigation or monitoring measures may be proposed as a part of risk management (Calow, 1998).

\section{Tier 3 - Refined risk assessment}

In Tier 3, extended laboratory tests, microcosm studies or even targeted (semi-)field experiments can be considered, as they represent conditions closer to those found in the field. Tier 3 studies are often laborious, and the data they provide can be difficult to interpret without the information generated in lower tiers.

Based on all available data, hazard and exposure are compared, and if the risks evaluated are shown to be negligible or acceptable with reasonable certainty, or it is considered that enough information is available to make a regulatory decision, the risk assessment can stop at this tier. If on the other hand the conclusions obtained from the Tier 3 evaluation confirm that a potential risk from the GM plant to specific non-target organisms exists or further information is needed for decision-making, alternative refinements within the tier, risk management or monitoring may be considered. 


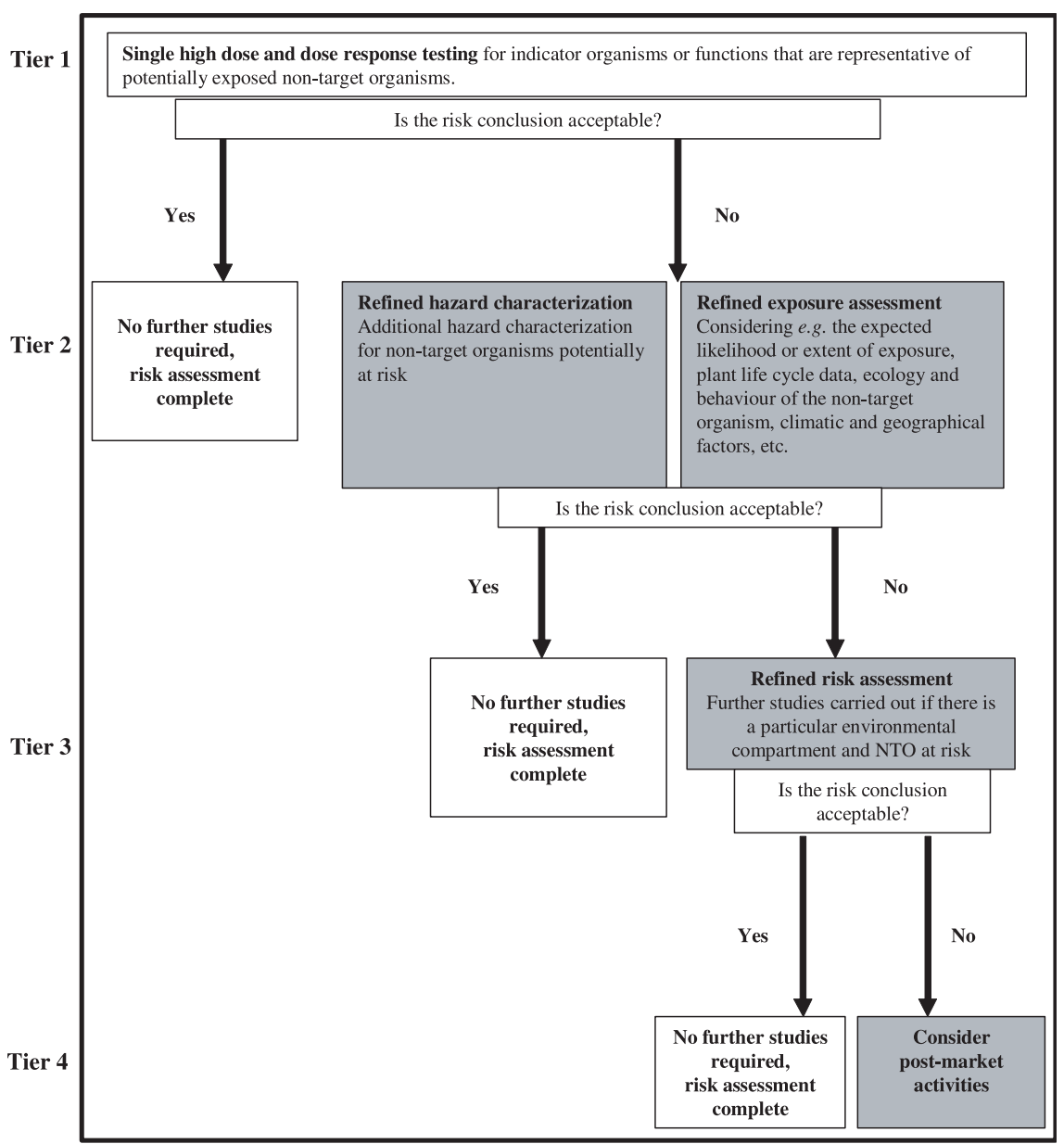

Figure 3. Decision tree for tiered safety testing of GM plants to non-target organisms (Tiers 1 to 4).

\section{Tier 4 - Post-market activities}

Post-market activities occur after risk has been characterized; they do not represent refinements of risk as occur in Tiers 1 to 3 and can be triggered either to address specific concerns or as a regulatory requirement. Such activities may include for example case-specific monitoring in accordance with Annex VII of Directive 2001/18/EC or monitoring literature for new information. Based on the information acquired in Tier 4 , conclusions from earlier tiers may be revisited.

\section{CONCLUSION}

The approach proposed here by the Technical Advisory Group of EuropaBio's Plant Biotechnology Unit for conducting non-target organism risk assessment for GM plants is based on the fundamental steps of risk evaluation, namely hazard and exposure assessment. It follows a systematic scientific tiered approach, where knowledge and information acquired in lower tiers is used to direct data collection in higher tiers, on a case-by-case basis.

The proposed environmental risk assessment process uses the conventional non-GM plant as the most appropriate baseline for comparison. When a significant risk to non-target organisms is identified or uncertainty remains at the end of the tiered risk assessment process, risk mitigation or risk management measures, including post-market monitoring activities, must be taken into consideration as necessary. This approach is consistent with the broader guidance published in the EU and other world areas.

Received March 14, 2006; accepted November 30, 2006. 


\section{REFERENCES}

Andow D and Zwahlen C (2006) Assessing environmental risks of transgenic plants. Ecol. Lett. 9: 196-214

Barret KL, Grandy N, Harrison EG, Hassan S, Oomen P (1994) Guidance document on regulatory testing procedures for pesticides with non-target arthropods. Society of Environmental Toxicology and Chemistry (SETAC) Europe. From the European Standard Characteristics of Beneficials Regulatory Testing (ESCORT I) Workshop, March 1994

BSP (2000) Cartagena Protocol on Biosafety to the Convention on Biological Diversity. http://www.biodiv.org/biosafety/ protocol.asp

Calow P (1998) Handbook of Environmental Risk Assessment and Management. In Calow P, ed, Blackwell Science, Oxford, UK

Candolfi M, Barret KL, Campbell PJ, Forster N, Grandy N, Huet MC, Lewis G, Oomen PA, Schmuck R, Vogt H (2000) Guidance document on regulatory testing and risk assessment procedures for plant protection products with nontarget arthropods. From the European standard characteristics of non-target arthropod regulatory testing (ESCORT II) Workshop, March 2000

Commission Decision 2002/623/EC of 24 July 2002 establishing guidance notes supplementing Annex II to Directive 2001/18/EC of the European Parliament and of the Council on the deliberate release into the environment of genetically modified organisms and repealing Council Directive 90/220/EEC. Official Journal of the European Communities L 200/22-33 (30.7.2002)

Council Decision 2002/811/EC of 3 October 2002 establishing guidance notes supplementing Annex VII to Directive 2001/ 18/EC of the European Parliament and of the Council on the deliberate release into the environment of genetically modified organisms and repealing Council Directive 90/220/ EEC. Official Journal of the European Communities L 280/ 27-36 (18.10.2002)

Directive 2001/18/EC of 12 March 2001 on the deliberate release into the environment of genetically modified organisms and repealing Council Directive 90/220/EC. Official Journal of the European Communities L 106/1-38 (17.4.2001)

Dutton A, Romeis J, Bigler F (2003) Assessing the risks of insect resistant transgenic plants on entomophagous arthropods: Bt maize expressing Cry1 $\mathrm{Ab}$ as a case study. BioControl 48: 611-636

EC (2000) Report of the Scientific Steering Committee's Working Group on Harmonisation of Risk Assessment Procedures in the Scientific Committees advising the European Commission in the area of human and environmental health - 26-27 October 2000. http:// europa.eu.int/comm/food/fs/sc/ssc/out83_en.pdf

EFSA (2004) Guidance document of the Scientific Panel on Genetically Modified Organisms for the risk assessment of genetically modified plants and derived food and feed. The EFSA Journal 99: 1-94

Marvier M (2002) Improving risk assessment for non-target safety of transgenic crops. Ecol. Applications 12: 11191124

Newman NC (1998) In Fundamentals of Ecotoxicology. Ann Arbor Press, Chelsea, MI

Nickson T, McKee M (2002) Ecological assessment of crops derived through biotechnology. In Biotechnology and Safety Assessment, 3rd edition, Thomas J.A. and Fuchs R.L., eds, Academic Press, Amsterdam, pp 233-252

OECD (1993a) Safety considerations for biotechnology: scaleup of crop plants. http://www.oecd.org/dataoecd/26/26/ 1958527.pdf?channelId=34537\&homeChannelId=33703\&fil eTitle $=$ Safety + Considerations + for + Biotechnology + Scale up+of+Crop+Plants

OECD (1993b) Safety evaluation of foods derived by modern biotechnology: concept and principles. http://www.oecd.org/ dataoecd/57/3/1946129.pdf?channelId=34537\&

homeChannelId $=33703 \&$ fileTitle $=$ Safety + Evaluation + of + Foods+Derived+by+Modern+Biotechnology+-+Concepts tand+Principles

Regulation (EC) 1829/2003 of the European Parliament and the Council of 22 September 2003 on genetically modified food and feed. Official Journal of the European Communities L 268/1-23 (18.10.2003)

Rose RI (2006) Tier-based testing for potential effects of proteinaceous insecticidal plant-incorporated protectants on non-target arthropods in the context of regulatory risk assessments. IOBC WPRS Bulletin 29: 145-152

Schuler T, Poppy GM, Denholm I (2000) Recommendations for assessing effects of GM crops on non-target organisms. British Crop Protection Council Conference: Pest and Diseases 3: 1221-1228

US EPA (1998) Guidelines for Ecological Risk Assessment. U.S. Environmental Protection Agency, Risk Assessment Forum, Washington, DC, 175 pp. http://oaspub.epa.gov/eims/ eimsapi.dispdetail?deid $=12460$

US EPA (1999) Draft ECOFRAM Aquatic Report. P. Hendley and J. Giddings, eds. http://www.epa.gov/oppefed1/ecorisk/ aquareport.pdf

US EPA (2001) Biopesticides Registration Action Document Bacillus thuringiensis Plant Incorporated Protectants. http:// www.epa.gov/oppbppd1/biopesticides/pips/bt_brad.htm

Van Leuven CJ (1996) In Risk Assessment of Chemicals: An Introduction

WHO/FAO (2000) Safety aspects of genetically modified foods of plant origin. Report of a joint FAO/WHO expert consultation on foods derived from biotechnology, 29. http:// www.fao.org/es/ESN/food/pdf/gmreport.pdf

Wilkinson MJ, Sweet JB, Poppy G (2003) Preventing the regulatory log jam; the tiered approach to risk assessments. Trends Plant Sci. 8: 208-212 